\title{
The formation of pre-crystallization oligomers in protein solutions during crystal growth
}

\author{
K.B. Ilina' ${ }^{1}$, A.S. Boikova ${ }^{1}$, M.A. Marchenkova' ${ }^{1}$, P.V. Konarev ${ }^{1}$, Yu.V. Pisarevsky' ${ }^{1}$, Yu.A. Dyakova ${ }^{2}$, M.V. Kovalchuk ${ }^{2}$

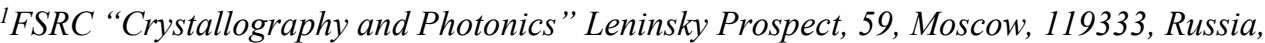 \\ ${ }^{2}$ NRC «Kurchatov Institute», 1, Akademika Kurchatova pl., Moscow, 123182, Russia
}

ilina-ks@mail.ru

The formation of structured oligomers in protein solutions during crystallization by SAXS and SANS methods are shown. The experimental SAXS and SANS data are processed using models of oligomers extracted from the crystal structure. Octamers and dimers are formed in a crystallization solution during growth of tetragonal lysozyme crystals with the addition of precipitant $\mathrm{NaCl}$ [1]. The volume fraction of octamers increases with the protein concentration increase and the temperature decrease. Addition of $\left(\mathrm{NH}_{4}\right)_{2} \mathrm{SO}_{4}$ or $\mathrm{NaNO}_{3}$ as precipitants is shown to induce the formation of a significant fraction of protein dimers in proteinase $\mathrm{K}$ solution during the growth of tetragonal crystals [2]. Hexamers are formed in crystallization solution during hexagonal crystal growth of thermolysin [3]. The hexameric volume fraction increases when the supersaturation conditions are met, i.e. when the temperature decreases and the precipitant $\left(\left(\mathrm{NH}_{4}\right)_{2} \mathrm{SO}_{4}\right)$ concentration increases. The formation of transaminase dodecamers is shown in crystallization solution with addition of precipitant $\mathrm{NaCl}$ [4]. Protein crystal and its oligomers are presented in the figure 1-a. Oligomers may act as building blocks in the growth of proteins single crystals. Also, the influence of solvent type $\left(\mathrm{H}_{2} \mathrm{O}\right.$ and $\left.\mathrm{D}_{2} \mathrm{O}\right)$ on structure crystallization solution was investigated [5]. The dimer and octamer formation in crystallization solution in $\mathrm{H}_{2} \mathrm{O}$ and $\mathrm{D}_{2} \mathrm{O}$ is shown.

a)
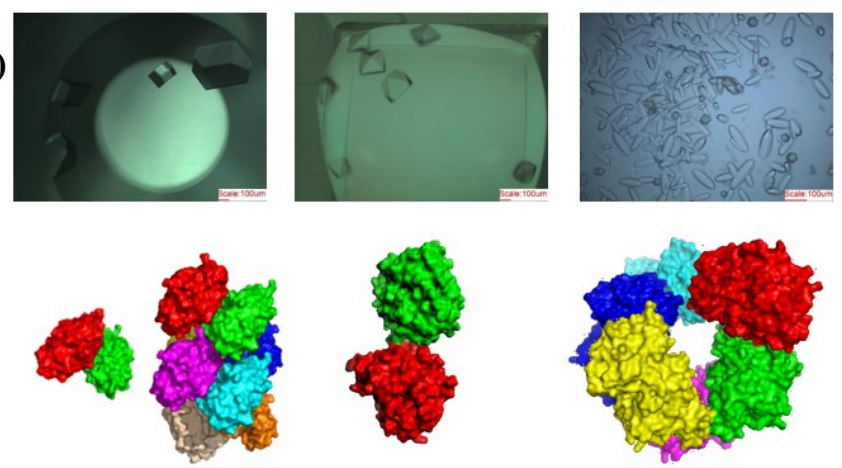

Octamer Lysozyme

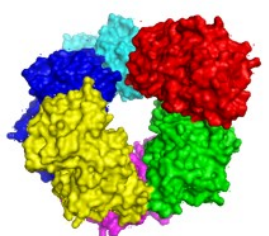

hexamer Thermolysin
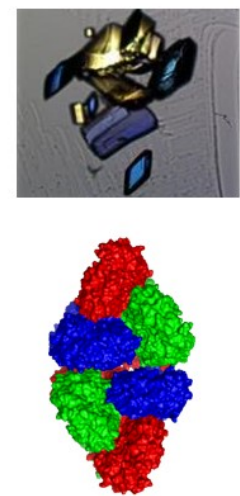

dodecamer Transaminase

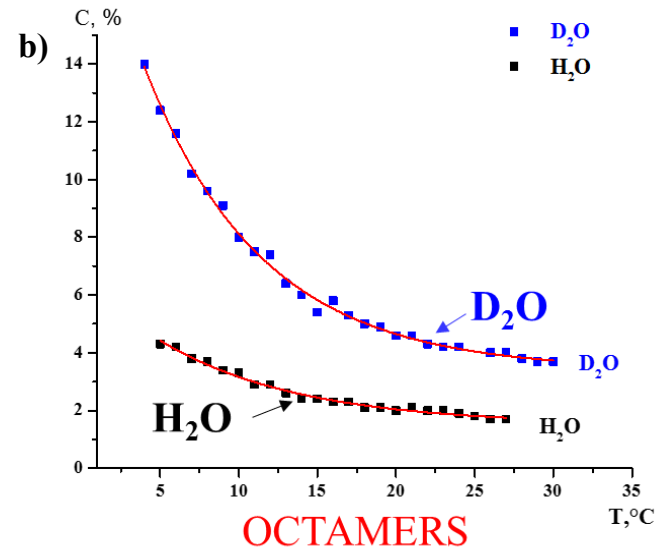

Figure 1. a) protein crystals and oligomers (octamer, dimer, hexamer, dodecamer) in crystallization solution of lysozyme, proteinase K, thermolysin, transaminase, b) volume fraction of octamers in lysozyme crystallization solution in $\mathrm{D}_{2} \mathrm{O}$ and $\mathrm{H}_{2} \mathrm{O}$ with temperature.

The volume fraction of octamers increases with a decrease in temperature in both type of solvent (figure 1-b). Concentration of octamer is higher in crystallization solution in $\mathrm{D}_{2} \mathrm{O}$ then in $\mathrm{H}_{2} \mathrm{O}$.

[1] Boikova, A.S., Dyakova, Y.A., Ilina, K.B. et all. (2017) Acta Crystallographica Section D: Structural Biology, 73 (7), 591

[2] Boikova, A.S., D’yakova, Y.A., Il'ina, K.B. et all.Crystallography Reports, 63 (6), 865

[3] Kovalchuk, M.V., Boikova, A.S., Dyakova, Yu.A. et all. (2019) Journal of Biomolecular Structure and Dynamics, 37 (12), 3058

[4] Marchenkova, M.A., Konarev, P.V., Rakitina, T.V. et all. (2019) Journal of Biomolecular Structure and Dynamics, in press.

[5] Boikova, A.S., D’yakova, Y.A., Il'ina, K.B. et all. (2017) Crystallography Reports, 62 (6), 837.

\section{Keywords: Protein Oligomers, Protein solution, Protein Crystallization, Crystal Growth, SAXS}

This study was supported in part by the Ministry of Science and Higher Education within the State assignment FSRC «Crystallography and Photonics» RAS and by the Russian Foundation for Basic Research (project number 19-29-12042 mk). 